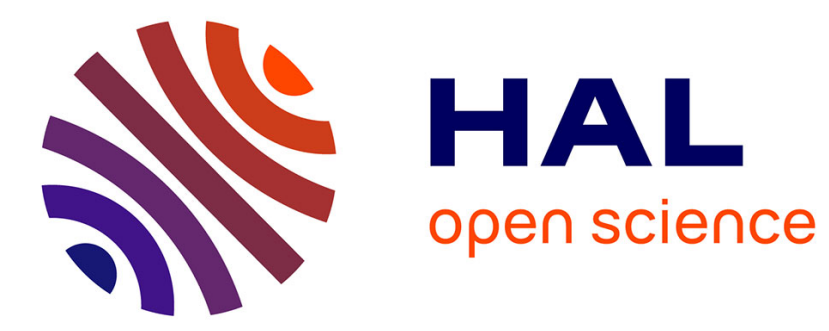

\title{
Almost common value auctions and discontinuous equilibria
}

Gisèle Umbhauer

\section{To cite this version:}

Gisèle Umbhauer. Almost common value auctions and discontinuous equilibria. Annals of Operations Research, 2015, 225 (1), pp.125-140. 10.1007/s10479-013-1377-5 . hal-01735849

\section{HAL Id: hal-01735849 \\ https://hal.univ-lorraine.fr/hal-01735849}

Submitted on 2 Sep 2020

HAL is a multi-disciplinary open access archive for the deposit and dissemination of scientific research documents, whether they are published or not. The documents may come from teaching and research institutions in France or abroad, or from public or private research centers
L'archive ouverte pluridisciplinaire HAL, est destinée au dépôt et à la diffusion de documents scientifiques de niveau recherche, publiés ou non, émanant des établissements d'enseignement et de recherche français ou étrangers, des laboratoires publics ou privés. 


\title{
Almost common value auctions and discontinous equilibria
}

\author{
Gisèle Umbhauer* \\ The final publication is available at link.springer.com \\ Published in Annals of Operations Research 225,1,125-140 (2015) \\ DOI 10.1007/s10479-013-1377-5
}

\begin{abstract}
In almost common value auctions, even a small private payoff advantage is usually supposed to have an explosive effect on the outcomes in a second-price sealed-bid common value auction. According to Bikhchandani (1988) and Klemperer (1998) the large set of equilibria obtained for common value auction games drastically shrinks, so that the advantaged player always wins the auction, at a price that sharply decreases the seller's payoff. Yet this result has not been observed experimentally. In this paper, we show that Bikhchandani's equilibria are not the only equilibria of the game. By introducing discontinuities in the bids, we establish a new family of perfect equilibria with interesting properties, among them: (i) the advantaged bidder does no longer win the auction regardless of her private information, (ii) she may pay a much higher price than in Bikhchandani's equilibria, (iii) there is no ex-post regret, (iv) the intersection with level- $k$ reasoning is not empty. We also show that a private advantage limits the number of possible discontinuities: one can introduce any number of discontinuities in the common value auction, but this is not possible in presence of a private advantage.
\end{abstract}

Keywords Common value auction - Second-price sealed-bid auction - Nash equilibrium Perfect equilibrium - level-k reasoning

\section{Introduction}

In almost common value auctions, one player has a valuation advantage over the other bidders. In this paper we focus on the two-player wallet game. In this game, two bidders participate in an auction of an item of value $\mathrm{V}$. Player $\mathrm{i}, \mathrm{i}=1,2$, privately observes a signal $\mathrm{x}_{\mathrm{i}}$ $\in[0,1]$ i.i.d. drawn from a distribution function on $[0,1]$. In the (common value) wallet game, $\mathrm{V}=\mathrm{x}_{1}+\mathrm{x}_{2}$. In the almost common value auctions setting, player 2 , the regular player, values the wallet at $\mathrm{x}_{1}+\mathrm{x}_{2}$, whereas player 1 , the advantaged player, has an additional private value $\mathrm{K}$ for the wallet, so that she values it at $\mathrm{x}_{1}+\mathrm{x}_{2}+\mathrm{K}$.

In a similar context, Bikhchandani (1988) showed that, in a second-price sealed-bid almost common value auction, the equilibria obtained for $\mathrm{K}$ close to 0 are sharply different from those obtained for $K=0$. More precisely, the large set of equilibria obtained for $K=0$ drastically shrinks when $\mathrm{K}$ becomes positive: the advantaged player always wins the auction, and the price she pays is very low, at most $\mathrm{x}_{2}+\mathrm{K}$, much lower than, for example, the price,

\footnotetext{
* Bureau d'Economie Théorique et Appliquée, University of Strasbourg, Strasbourg, France e-mail : umbhauer@unistra.fr
} 
$2 \mathrm{x}_{2}$, paid in the symmetric equilibrium obtained for $\mathrm{K}=0$. Yet this explosive effect has never been observed experimentally, even if the subjects were experienced, i.e. had previously learned to overcome the winner's curse effect in common value auctions (see Rose and Kagel 2008; Avery and Kagel 1997; Rose and Levin 2008).

In this paper, we propose a game theoretic explanation for the gap between theory and experimentally observed behaviour. We simply show that Bikhchandani's equilibria are not the only equilibria of the two-player second-price sealed-bid almost common value auction. In fact, previous papers (Bikhchandani 1988; Klemperer 1998) only focused on continuous equilibria, i.e. equilibria such that the player's bid continuously depends on her private information. By allowing some discontinuity, we establish a new family of Nash equilibria, in the common value auction game and in the almost common value auction game. These new equilibria have interesting properties. In these equilibria, the advantaged bidder does no longer win the auction regardless of her private information, and, when she wins, she may pay a much higher price than in Bikhchandani's equilibria. The equilibria are perfect equilibria and there is no ex-post regret for both the winner and the loser. These equilibria also allow some naïve behaviour: especially, they give partial support to bids that simply add to the private information the expected value of the opponent's information. Moreover, the intersection between these equilibria and level-k reasoning is not empty.

As far as we know, nobody worked on a similar approach up to now. Levin and Kagel (2005) managed to dampen the explosive effect by considering more than one regular bidder, in order to affect the second-price bidding logic which is responsive to this change. In our work, we do not change the strategic context of the two player wallet game, and so we show that it is not necessary to introduce more players to dampen Bikhchandani's explosive effect.

Yet this does not mean that the presence of an advantaged bidder has only a small impact on the equilibria. In particular, we show that it is possible, in the common value auction, to introduce any number of discontinuities, so that the symmetric continuous equilibrium - in which each player bids twice her private signal - becomes a limit equilibrium of the set of discontinuous equilibria. This, however, is not possible in the almost common value auction: in this game, one can only introduce one discontinuity in each bidder's strategy.

The paper is organised as follows. We first focus on common value auctions. In section 2 , we propose a new family of discontinuous Nash equilibria for these games. We first introduce one discontinuity in each player's bid function (Proposition 1) before introducing any number of discontinuities (Proposition 2). And we show that a limit equilibrium of this new family is the well-known symmetric continuous equilibrium $E_{S}$, where each player of type $\mathrm{x}$ plays $2 \mathrm{x}$ (Proposition 3).

We then consider almost common value auctions. In section 3 we show that discontinuous equilibria with one discontinuity also exist in the almost common value auction (Proposition 4) but that it is impossible to construct equilibria with more than one discontinuity in each bid function, even if one introduces nonlinear bid functions (Proposition 5). In section 4 we comment the economic and strategic properties of the equilibria with one discontinuity, when $\mathrm{K} \neq 0$. We show that the advantaged bidder does not win the auction regardless of her private information and that the equilibrium does not necessarily favour the advantaged player. We also show that the advantaged player may pay a much higher price upon winning than in Bikhchandani's equilibria. In section 5 we expose additional properties. We show that the 
new equilibria are perfect (Proposition 6); we also relate our family of equilibria to a naïve bidding and to level-k reasoning (Crawford and Iriberri 2007). We conclude in section 6.

\section{Discontinuous equilibria in the common value auction}

It is well known (see e.g. Avery and Kagel 1997) that the symmetric Nash equilibrium $E_{S}$ in which each player bids twice her private signal - is not the only Nash equilibrium of the second-price sealed-bid (common value) wallet game. But the bids in the other Nash equilibria are always continuous in the private signal, as in $\mathrm{E}_{S}$. By contrast, we propose Nash equilibria with discontinuous bids.

\subsection{Equilibria with one discontinuity}

\section{Proposition 1}

In the second-price sealed-bid (common value) wallet game $(\mathrm{K}=0)$, all the following profiles of strategies are Nash equilibria with no weakly dominated strategies:

\begin{tabular}{|c|c|c|c|c|}
\hline Player i bids & $b_{i}\left(x_{i}\right)$ & $\begin{array}{l}=x_{i}+1 \\
=x_{i}+d\end{array}$ & $\begin{array}{l}\text { if } x_{i}>c \\
\text { if } x_{i} \leq c\end{array}$ & $\begin{array}{l}\text { with } 0 \leq \mathrm{c} \leq 1 \\
\text { with } 0 \leq \mathrm{d} \leq 1\end{array}$ \\
\hline Player j bids & $b_{j}\left(x_{j}\right)$ & $\begin{array}{l}=x_{j}+c \\
=x_{j}\end{array}$ & $\begin{array}{l}\text { if } x_{j} \geq d \\
\text { if } x_{j}<d\end{array}$ & \\
\hline
\end{tabular}

Proof: Let us fix, without loss of generality, $i=1$ and $j=2$.

We first establish that $\mathrm{b}_{1}\left(\mathrm{x}_{1}\right)$ is a best response:

If $\mathrm{x}_{1}>\mathrm{c}$ player 1 best replies against any type ${ }^{1}$ of player 2 because:

- First she wins against any type of player 2, because $\mathrm{x}_{1}+1>\mathrm{c}+1$ and player 2 never bids more than $\mathrm{c}+1$.

- Second, she earns a positive payoff by winning, because she gets either $\mathrm{x}_{1}+\mathrm{x}_{2}-\mathrm{x}_{2}-\mathrm{c}>0$ or $\mathrm{x}_{1}+\mathrm{x}_{2}-\mathrm{x}_{2}>0$, depending on player 2's type. And the payoff she gets cannot be higher, because in a second-price auction the price paid is player 2's bid.

If $\mathrm{x}_{1} \leq \mathrm{c}$ :

- She loses against any type of player 2 such that $x_{2}>d$, because $x_{1}+d \leq c+d<x_{2}+c$. And losing gives her the best payoff, 0 , because winning would lead to the payoff $\mathrm{x}_{1}+\mathrm{x}_{2}-$ $\mathrm{x}_{2}-\mathrm{c} \leq 0$.

- She wins against any type of player 2 such that $\mathrm{x}_{2}<\mathrm{d}$, because $\mathrm{x}_{2}<\mathrm{d} \leq \mathrm{x}_{1}+\mathrm{d}$, and she gets a positive or null payoff by winning, because $\mathrm{x}_{1}+\mathrm{x}_{2}-\mathrm{x}_{2} \geq 0$; and this payoff can not be higher, given that it does only depend on player 2 's bid' 2 .

- If $\mathrm{x}_{1}<\mathrm{c}$, then she loses against player 2 of type $\mathrm{d}$ because $\mathrm{x}_{1}+\mathrm{d}<\mathrm{c}+\mathrm{d}$, and losing gives her the best payoff, 0 , because winning would lead to the payoff $\mathrm{x}_{1}+\mathrm{x}_{2}-\mathrm{x}_{2}-\mathrm{c}<0$. But if $\mathrm{x}_{1}=\mathrm{c}$, she makes the same bid as player 2 of type $\mathrm{d}$; Proposition 1 does not specify how the wallet is shared in case of a tie. But this is of no importance because player

\footnotetext{
${ }^{1}$ We often refer to $x_{i}$, the private signal of player $i$, as the type of player $i, i=1,2$.

${ }^{2}$ In what follows we do no longer add the observation "and this payoff cannot be higher, because the payoff, by winning, does only depend on the opponent's bid".
} 
1 gets a null payoff from getting the wallet, and she cannot get a positive payoff by bidding in a different way.

We now establish that $\mathrm{b}_{2}\left(\mathrm{x}_{2}\right)$ is a best response:

If $\mathrm{x}_{2} \geq \mathrm{d}$ :

- Player 2 loses against any type of player 1 such that $x_{1}>c$ (see above). And he is best off losing, because winning would lead to the payoff $\mathrm{x}_{2}+\mathrm{x}_{1}-\mathrm{x}_{1}-1 \leq 0$.

- he wins against player 1 if $\mathrm{x}_{1}<\mathrm{c}$ (see above); and he is best off winning because he gets $\mathrm{x}_{2}+\mathrm{x}_{1}-\mathrm{x}_{1}-\mathrm{d} \geq 0$.

- if $\mathrm{x}_{2}>\mathrm{d}$, then he wins against $\mathrm{x}_{1}=\mathrm{c}$, and he is best off winning because he gets $\mathrm{x}_{2}+\mathrm{x}_{1}$ $\mathrm{x}_{1}-\mathrm{d}>0$. But, if $\mathrm{x}_{2}=\mathrm{d}$, then he makes the same bid as player 1 of type $\mathrm{c}$; Proposition 1 does not specify how the wallet is shared in case of a tie. But, as above, this is of no importance because player 2 gets a null payoff from getting the wallet, and he cannot get a positive payoff by bidding in a different way.

If $\mathrm{x}_{2}<\mathrm{d}$, he loses against any type of player 1 (see above), and he is best off losing because, by winning, he would get $\mathrm{x}_{2}+\mathrm{x}_{1}-\mathrm{x}_{1}-\mathrm{d}<0$, if facing a player 1 type $\mathrm{x}_{1} \leq \mathrm{c}$, and he would get $\mathrm{x}_{2}+\mathrm{x}_{1}-\mathrm{x}_{1}-1<0$ if facing a player 1 type $\mathrm{x}_{1}>\mathrm{c}$.

The equilibrium contains no weakly dominated strategy given that each player's bid is between her/his type $\mathrm{x}$ and $\mathrm{x}+1$.

The proof highlights two properties of these equilibria:

- The equilibria hold regardless of the distribution functions on $[0,1]$.

- A player, when s/he wins, not only gets a positive expected payoff, but s/he gets a positive payoff with each losing opponent. And the reverse is true when s/he loses the auction: by winning, s/he would not only get a negative expected payoff, but s/he would get a negative payoff with any type of (winning) opponent. This property is usually referred to as the no expost regret property (see e.g. Avery and Kagel 1997).

\subsection{Equilibria with a finite number of discontinuities}

The equilibria of Proposition 1 assume one discontinuity in each bidding strategy ${ }^{3}$. The following proposition extends this result to any finite number of discontinuities.

\section{Proposition 2}

$\mathrm{N}$ is an integer, $c_{i}$ and $d_{i}, i$ from 1 to $\mathrm{N}$, are two increasing sequences of real numbers such that $0 \leq \mathrm{c}_{1}<\ldots<\mathrm{c}_{\mathrm{N}} \leq 1$ and $0 \leq \mathrm{d}_{1}<\ldots<\mathrm{d}_{\mathrm{N}} \leq 1$.

In the second-price sealed-bid (common value) wallet game $(\mathrm{K}=0)$, all the following profiles of strategies are Nash equilibria with no weakly dominated strategies:

Player i bids $\quad b_{i}\left(x_{i}\right)=x_{i}+1 \quad$ if $x_{i}>c_{N}$

$$
=\mathrm{x}_{\mathrm{i}}+\mathrm{d}_{\mathrm{N}-\mathrm{k}} \quad \text { if } \mathrm{c}_{\mathrm{N}-\mathrm{k}-1}<\mathrm{x}_{\mathrm{i}} \leq \mathrm{c}_{\mathrm{N}-\mathrm{k}} \text { with } \mathrm{k} \text { from } 0 \text { to } \mathrm{N}-2
$$

\footnotetext{
${ }^{3}$ To be more precise, there is one discontinuity for each player provided $c \neq 1$ and $d \neq 0$. For $c=1$, player $i$ only bids $\mathrm{x}_{\mathrm{i}}+\mathrm{d}$ (no discontinuity), for $\mathrm{d}=0$, player $\mathrm{j}$ only bids $\mathrm{x}_{\mathrm{j}}+\mathrm{c}$ (no discontinuity).
} 


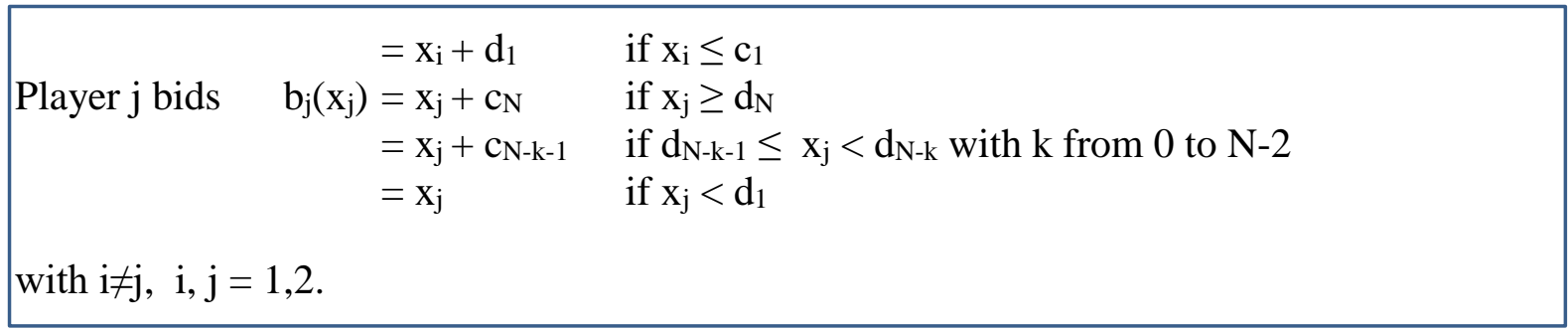

Proof : The proof of Proposition 2 follows the one of Proposition 1 and is reported in Appendix A.

It immediately follows from the proof that these equilibria, like the ones of Proposition 1, hold regardless of the distribution functions on $[0,1]$ and satisfy the no ex-post regret property.

Clearly Proposition 2 introduces $\mathrm{N}$ discontinuities in each player's strategy, provided $\mathrm{c}_{\mathrm{N}} \neq 1$ and $\mathrm{d}_{1} \neq 0$ (if $\mathrm{c}_{\mathrm{N}}=1$, respectively $\mathrm{d}_{1}=0$, player i's strategy, respectively player $\mathrm{j}$ 's strategy, has only N-1 discontinuities).

Let us look at a particular equilibrium of this family with $\mathrm{N}=(1-\Delta) / \Delta$, where $\Delta$ is a small positive real s.t. $\mathrm{N}$ is an integer, $\mathrm{c}_{\mathrm{N}-\mathrm{k}}=\mathrm{d}_{\mathrm{N}-\mathrm{k}}=1-(\mathrm{k}+1) \Delta$, with $\mathrm{k}$ from 0 to $\mathrm{N}-2, \mathrm{c}_{1}=\mathrm{d}_{1}=\mathrm{c}_{\mathrm{N}-(\mathrm{N}-1)}=$ $\mathrm{d}_{\mathrm{N}-(\mathrm{N}-1)}=1-\mathrm{N} \Delta=\Delta$. We get:

$$
\begin{aligned}
& \text { Player i bids } \quad b_{i}\left(x_{i}\right)=x_{i}+1 \quad \text { if } x_{i}>1-\Delta \\
& =\mathrm{x}_{\mathrm{i}}+1-(\mathrm{k}+1) \Delta \text { if } 1-(\mathrm{k}+2) \Delta<\mathrm{x}_{\mathrm{i}} \leq 1-(\mathrm{k}+1) \Delta \text { with } \mathrm{k} \text { from } 0 \text { to } \mathrm{N}-2 \\
& =\mathrm{x}_{\mathrm{i}}+\Delta \quad \text { if } \mathrm{x}_{\mathrm{i}} \leq \Delta \\
& \text { Player } \mathrm{j} \text { bids } \quad \mathrm{b}_{\mathrm{j}}\left(\mathrm{x}_{\mathrm{j}}\right)=\mathrm{x}_{\mathrm{j}}+1-\Delta \quad \text { if } \mathrm{x}_{\mathrm{j}} \geq 1-\Delta \\
& =\mathrm{x}_{\mathrm{j}}+1-(\mathrm{k}+2) \Delta \text { if } 1-(\mathrm{k}+2) \Delta \leq \mathrm{x}_{\mathrm{j}}<1-(\mathrm{k}+1) \Delta \text { with } \mathrm{k} \text { from } 0 \text { to } \mathrm{N}-2 \\
& =\mathrm{x}_{\mathrm{j}} \quad \text { if } \mathrm{x}_{\mathrm{j}}<\Delta
\end{aligned}
$$

It immediately follows that this equilibrium converges to the well-known symmetric continuous equilibrium $\mathrm{E}_{S}$ in which each player of type $\mathrm{x}$ simply bids $2 \mathrm{x}$, when $\Delta$ goes to 0 . More precisely, player i bids slightly more than twice her type, and player $\mathrm{j}$ bids slightly less than twice his type. One can observe a slight advantage for player $\mathrm{i}$, who wins when $\mathrm{x}_{\mathrm{i}}=\mathrm{x}_{\mathrm{j}}$, in that player $\mathrm{i}$ bids slightly more than $2 \mathrm{x}_{\mathrm{i}}$ and player $\mathrm{j}$ bids slightly less than $2 \mathrm{x}_{\mathrm{j}}$.

\section{Proposition 3}

The set of discontinuous equilibria contains an equilibrium that converges to the continuous symmetric equilibrium $E_{S}$, in which each player bids twice her/his type.

\section{Discontinuous equilibria in the almost common value auction}

We now show to what extent the above propositions apply to the almost common value auction setting.

\subsection{Equilibria with one discontinuity}

We first extend the result of Proposition 1. We get: 


\section{Proposition 4}

In the second-price sealed-bid almost common value wallet game $(K \neq 0)$, all the following profiles of strategies are Nash equilibria with no weakly dominated strategies:

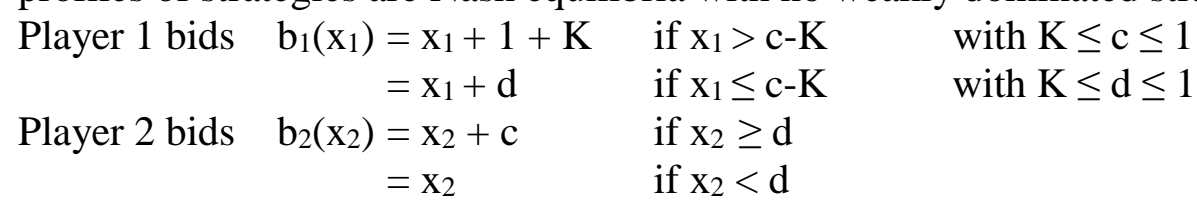

Proof: The proof of Proposition 4 follows the one of Proposition 1 and is reported in Appendix B.

It immediately follows from the proof that these equilibria, like the ones in Proposition 1, hold regardless of the distribution functions on $[0,1]$ and satisfy the no ex-post regret property.

It also follows from Propositions 1 and 4 that the family of equilibria for $\mathrm{K} \geq 0$ is upper semi continuous at $K=0$. The family of equilibria for $K \neq 0$ converges, when $K$ goes to 0 , to the equilibria in Proposition 1, with $\mathrm{i}=1$ and $\mathrm{j}=2$.

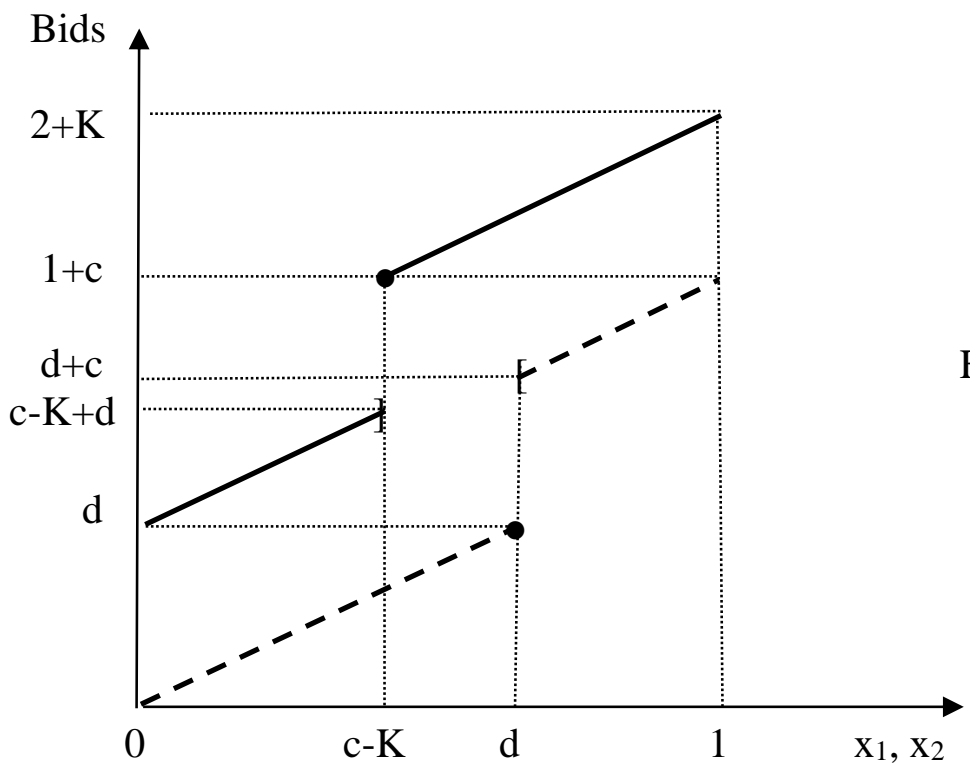

Legend of Figure 1: - means that the point is excluded, a bracket means that it is included. The full lines are player 1's bids, the dashed lines are player 2's bids.

Note that, in addition to be discontinuous, the players' bidding strategies have no bid in common. Figure 1 illustrates this property for $\mathrm{c}<\mathrm{d}$ (w.l.o.g.).

This property is important in that the reasoning that leads to Bikhchandani's explosive effect requires a common bid to hold (see e.g. Klemperer 1998; Rose and Levin 2008). 


\subsection{Non-existence of equilibria with more than one discontinuity}

One may conjecture that it is also possible to enlarge the set of equilibria of Proposition 4, in a way to come close to the set of equilibria of Proposition 2, when $K \neq 0$ and $K$ close to 0 . This, however, is not possible.

\section{Proposition 5:}

When $\mathrm{K} \neq 0$ it is not possible to get equilibria that generalize those of Proposition 4, with more than one discontinuity in each bid function and which satisfy the no ex-post regret property.

Proof: The proof of Proposition 5 is reported in Appendix C.

It follows from the proof that, even if we allow for any increasing continuous bid functions $b(x)$, neither three nor more subdivisions of the $[0,1]$ interval are possible when $\mathrm{K}>0$. Each discontinuous Nash equilibrium strategy with no ex-post regret contains at most one discontinuity.

Thus, if $\mathrm{K}>0$, we cannot get a discontinuous Nash equilibrium with no ex-post regret close to the continuous symmetric equilibrium $\mathrm{E}_{\mathrm{s} .}{ }^{4}$

Yet introducing only one discontinuity in the bidders' strategies is enough to counter Bikhchandani (1988) and Klemperer(1998)'s negative explosive effect. In the following two sections, we discuss the properties of the new set of equilibria of Proposition 4.

\section{Winners and seller's expected revenues in the almost common value auction}

\subsection{Winners}

It follows from Proposition 4 that both players can win the auction, depending on the values of $\mathrm{x}_{1}, \mathrm{x}_{2}, \mathrm{c}$ and $\mathrm{d}$. A possible equilibrium is displayed in Figure $2 \mathrm{a}$.

\footnotetext{
${ }^{4}$ One may wonder if allowing for ex-post regret may lead to Nash equilibria with more discontinuities. This is not the case. As long as discontinuities are introduced in linear bid functions by adding a constant to the bidder's type, that grows stepwise in the types, the resulting Nash equilibrium automatically satisfies the no ex-post regret property.

Two facts drive this result, the specificity of the second price auction logic and the discontinuity in the added constants. By construction of the bid functions, a player wins against some types of the opponent and loses against the higher types. But he cannot lose the auction against types of the opponent if winning yields a positive payoff: given that the winning bidder only pays the losing bid, he can choose to outbid these opponent's higher types as long as winning yields a positive payoff. By doing so, he earns additional positive payoffs with these higher types and he still gets the same payoff with the lower types, hence he raises his revenues. It follows that, in equilibrium, a player cannot lose the auction if winning yields a positive payoff. And he cannot win the auction if this yields a negative payoff. To raise his revenues in the latter case, the player should submit a bid that lies between the bid of the highest type he wins with a positive payoff and the bid of the lowest type he wins with a negative payoff. Such a bid always exists because of the way discontinuities are introduced. By submitting such a bid, the player would leave his payoff unchanged with lower types and would earn a zero payoff (instead of a negative one) with the higher types. It follows that each Nash equilibrium satisfies the no ex-post regret property.
} 


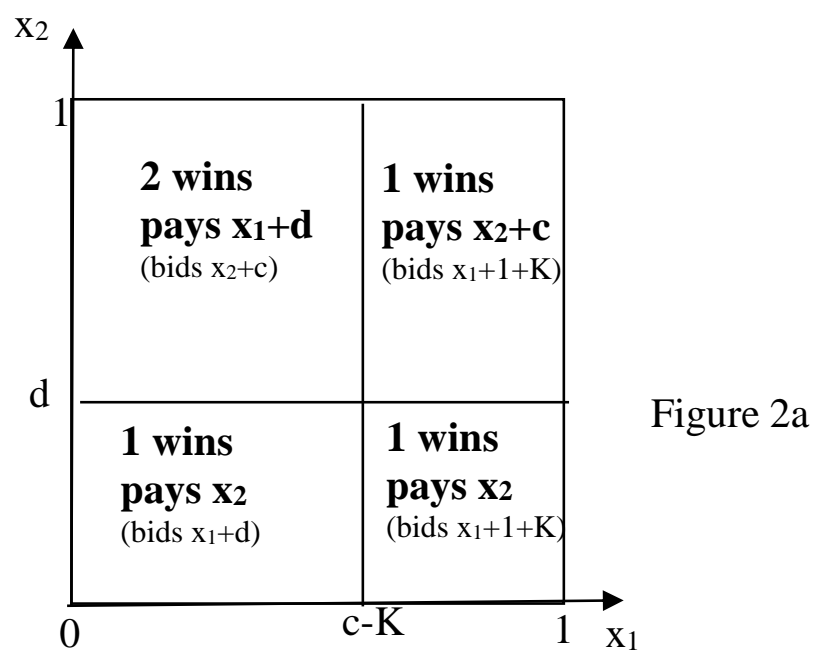

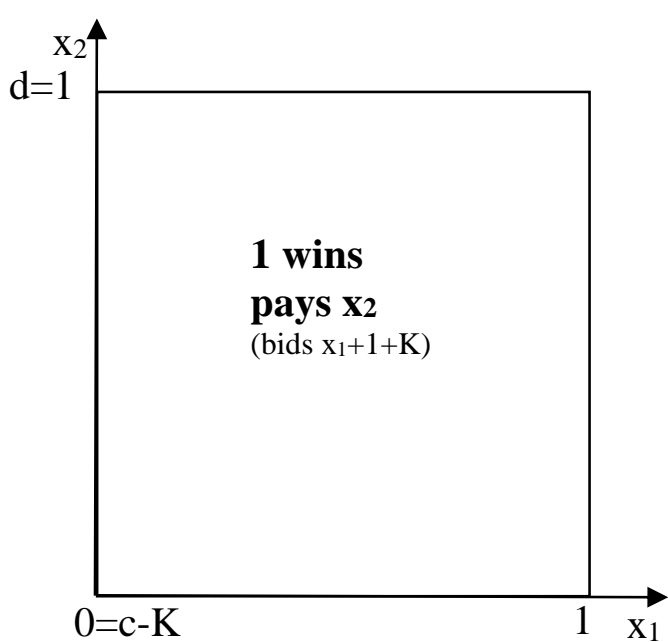

Figure $2 b$

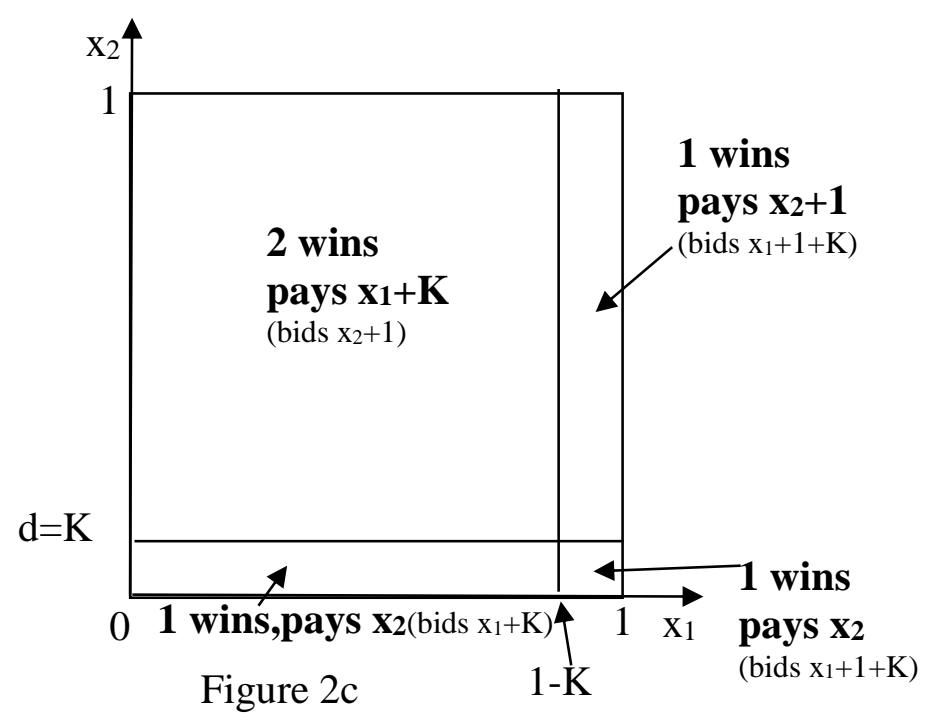

Legend of Figures $2 a, 2 b, 2 c:$ each area indicates which player wins the auction, what s/he pays, and what s/he bids.

It also follows that the equilibrium can favour the advantaged player 1 , namely if $\mathrm{c}=\mathrm{K}$ and $\mathrm{d}=1$ : in that case player 1 always ${ }^{5}$ wins the auction at price $\mathrm{x}_{2}$ (or at price $\mathrm{x}_{2}+\mathrm{K}$ when $\mathrm{x}_{2}=1$ ) (Figure 2b). This equilibrium illustrates the explosive effect announced by Bikhchandani (1988) and Klemperer (1998). Hence our family of equilibria includes the equilibria obtained by Bikhchandani (1988).

But the equilibrium can also favour the unadvantaged player 2, namely if $\mathrm{c}=1$ and $\mathrm{d}=\mathrm{K}$ (see Figure 2c); in this case, for $\mathrm{K}$ going to 0 , player 2 almost always wins the auction at the very low price $\mathrm{x}_{1}+\mathrm{K}$.

It follows from Figures $2 b$ and $2 c$ that $K$ close to 0 is compatible with much more symmetry between player 1 and player 2 than announced by Bikhchandani (1988) and Klemperer (1998). When K grows, the minimal areas in which player 1 wins the auction grow in size (because $d \geq K$, and $c-K \leq 1-K$ ), but in a proportional and not in an explosive way. So the symmetry only smoothly disappears as $\mathrm{K}$ grows. Moreover, since $\mathrm{d} \in[\mathrm{K}, 1]$, it also appears that upon winning, player 1 pays at least part of the time the price $\mathrm{x}_{2}+\mathrm{c}$, where $\mathrm{c}$ can be high,

\footnotetext{
${ }^{5}$ Except if $\mathrm{x}_{1}=0$ and $\mathrm{x}_{2}=1$ : in this special case, player 1 bids 1 , player 2 bids $1+\mathrm{K}$, player 2 wins the auction but pays 1 and his payoff is equal to 0 .
} 
going from $\mathrm{K}$ to 1 . So player 1 may pay a high price, especially when both $\mathrm{x}_{1}$ and $\mathrm{x}_{2}$ are high. So the explosive effect, both as regards the winning player and the price s/he pays, is not observed in this family.

\subsection{Seller's expected revenues}

The set of equilibria of Proposition 4 has an additional interesting property. The maximal payoff the seller can get with such an equilibrium, for uniform distributions on [0,1], is 35/54 when $\mathrm{K}$ goes to 0 , which is very close to $2 / 3(=36 / 54)$, the payoff obtained with the symmetric equilibrium $\mathrm{E}_{\mathrm{S}}$ obtained for $\mathrm{K}=0$, where each player bids $2 \mathrm{x}$ when her/his type is $\mathrm{x}$. Hence the introduction of $\mathrm{K}$ different from 0 does not induce the strong drop in the seller's payoff (at most $1 / 2$ when K goes to 0 ) observed in Bikhchandani's equilibrium. As a matter of fact, maximising on $\mathrm{d}$ and $\mathrm{c}$ the seller's payoff leads to the program:

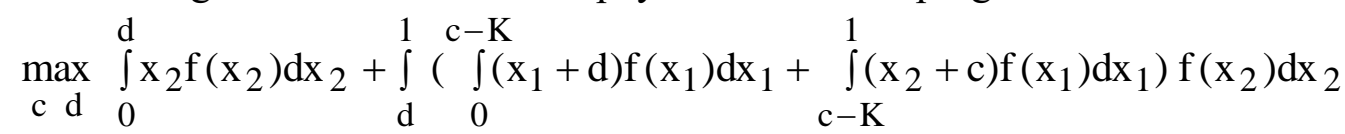

where $f\left(x_{1}\right)$ and $f\left(x_{2}\right)$ are the uniform distribution on $[0,1]$.

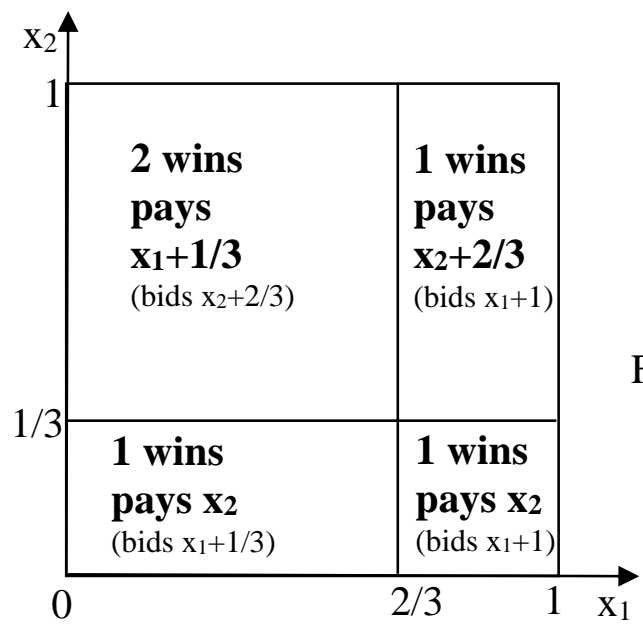

Figure 3

For $K$ close to 0 , this program leads to $c=2 / 3, d=1 / 3$ and a seller's payoff equal to $35 / 54$ (the equilibrium is displayed in Figure 3, with $\mathrm{K}=0$ ). This equilibrium more favours player 1 than player 2 , who respectively get $1 / 6+1 / 27$ and $1 / 6-1 / 54$, but these payoffs are not far from the Es payoff $1 / 6$ and much less asymmetric than those obtained in Bikhchandani's equilibria (close to $1 \frac{1}{2}$ for player 1 and close to 0 for player 2 ).

So, despite one discontinuity is not enough to come close to the $E_{S}$ behaviour, it is enough, at least for uniform distributions, to get a discontinuous equilibrium whose payoffs, for each player, are close to the Es ones.

\section{Further properties of the discontinuous equilibria in the almost common value auction}

In this section we first prove that the equilibria of Proposition 4 are perfect equilbria. Then we show that these equilibria give partial support to a naïve bidding behaviour, and that some of them relate to the concept of level-k reasoning. 


\subsection{Perfection}

The perfect equilibrium concept introduces perturbations on each action but is only defined for finite games. So, to study the perfectness of an equilibrium of our new set of equilibria, we change the structure of the game as follows. We assume that the set of types of each bidder is a discrete set of $\mathrm{T}$ types ranging from 0 to 1 (with $\mathrm{T}$ very large); we call $\mu$ the (small) increment between two adjacent types, and we choose $\mu$ so that $\mathrm{c}-\mathrm{K}$ and $\mathrm{d}$ are two types of the set of types; it thus follows that the closest higher type to a type $\mathrm{x}$ is $\mathrm{x}+\mu$. We then introduce a discrete set of bids, ranging from 0 to a high finite integer; the grid is chosen so that $\mathrm{x}, \mathrm{x}+\mathrm{c}, \mathrm{x}+\mathrm{d}, \mathrm{x}+1+\mathrm{K}$ are in the discrete set of bids, for any type $\mathrm{x}$ in the discrete set of types ${ }^{6}$. Within such a discrete setting, we get the following proposition.

\section{Proposition 6}

All the Nash equilibria of Proposition 4 are perfect equilibria (Selten1975).

\section{Proof: ${ }^{7}$}

Let us first consider player 1:

- For $\mathrm{x}_{1}>c-K$, i.e. $\mathrm{x}_{1} \geq c-K+\mu, \mathrm{b}_{1}\left(\mathrm{x}_{1}\right)=\mathrm{x}_{1}+1+\mathrm{K}$ is a best response against any perturbed strategy of player 2. Indeed, either $\mathrm{x}_{2}<\mathrm{d}$; if so, $\mathrm{b}_{1}\left(\mathrm{x}_{1}\right)$ is strictly higher than player 2 's bid, and player 1 is best off winning regardless of the small perturbations introduced (because she pays something close to $\mathrm{x}_{2}$ ). Or she competes with a type $\mathrm{x}_{2} \geq \mathrm{d}$, and this type bids something close to $\mathrm{x}_{2}+\mathrm{c}$. It follows that $\mathrm{b}_{1}\left(\mathrm{x}_{1}\right)$ is strictly higher than player 2 's bid, even if $\mathrm{x}_{2}=1$ when the perturbations go to 0 (because $\mathrm{c}+1+\mu$ is higher than a bid converging to $1+\mathrm{c}$ ). Moreover the payoff obtained is strictly positive, because even the lowest type $\mathrm{c}-\mathrm{K}+\mu$ gets a payoff close to $\mu$, when the perturbations go to 0 .

- If $\mathrm{x}_{1} \leq \mathrm{c}-\mathrm{K}$, then player 1 loses the auction against any $\mathrm{x}_{2} \geq \mathrm{d}$, regardless of the small perturbations introduced - because even $\mathrm{c}-\mathrm{K}+\mathrm{d}$ is below $\mathrm{d}+\mathrm{c}$. And player 1 is best off losing the auction, provided $\left(\mathrm{x}_{1}+\mathrm{x}_{2}+\mathrm{K}\right.$ - players 2 's bid $) \leq 0$. This condition is fulfilled for any $\mathrm{x}_{1}<\mathrm{c}-$ $\mathrm{K}$, because player 2 bids close to $\mathrm{x}_{2}+\mathrm{c}$. And for $\mathrm{x}_{1}=\mathrm{c}-\mathrm{K}$, for $\left(\mathrm{c}+\mathrm{x}_{2}-\right.$ player 2 's bid $)$ to be negative or null, we introduce perturbations such that player 2 bids a little more that $\mathrm{x}_{2}+\mathrm{c}$.

- If $\mathrm{x}_{1} \leq \mathrm{c}-\mathrm{K}$, player 1 wins the auction against $\mathrm{x}_{2}<$ d, i.e. $\mathrm{x}_{2} \leq \mathrm{d}-\mu$, and he still wins in a perturbed environment, because $\mathrm{x}_{1}+\mathrm{d} \geq \mathrm{d}$ and $\mathrm{x}_{2}$ 's bid is below $\mathrm{d}$ for small perturbations. And player 1 's payoff is positive regardless of the small perturbations introduced, because he gets something close to $\mathrm{x}_{1}+\mathrm{K}>0$, even for $\mathrm{x}_{1}=0$.

\footnotetext{
${ }^{6}$ In the original game, bids can go from 0 to infinity. But we could easily prove our propositions in a more restricted context where bids belong to an interval $[0,100]$ for example, given that non dominated bids never exceed $2+K$. Such a restriction ensures that the finite games can come as close as one wants to the original game.

${ }^{7}$ Before proving that the new profiles of strategies in Proposition 4 are perfect equilibria of the finite constructed games, it may be interesting to observe that they are automatically Nash equilibria of the finite games. This follows from the no ex-post regret property. We know that, in the original game, each type of player i plays optimally against each type of player $j(j \neq i \quad i, j=1,2)$ in $[0,1]$ : so s/he necessarily plays optimally against any type in the (restricted) finite set of types.
} 
Let us now consider player 2:

- If $\mathrm{x}_{2}<\mathrm{d}$, i.e. $\mathrm{x}_{2} \leq \mathrm{d}-\mu$, player 2 , by bidding $\mathrm{x}_{2}$, always bids less than any type $\mathrm{x}_{1}$. Indeed, even a player 1 of type $\mathrm{x}_{1}=0$ bids more than $\mathrm{d}-\mu$ for any small perturbations (because she bids something close to d). And player 2 is best off losing, because winning would only lead to a negative payoff regardless of the small perturbations on player 1's strategy.

- If $x_{2} \geq d$, bidding $x_{2}+c$ leads to lose against any $x_{1}>c-K$, i.e. $x_{1} \geq c-K+\mu$, for any small perturbations. And losing is the best strategy for any small perturbations on player 1's bid (because winning would lead to a payoff close to $\mathrm{x}_{2}-1-\mathrm{K}<0$ ).

- If $\mathrm{x}_{2} \geq \mathrm{d}$, bidding $\mathrm{x}_{2}+\mathrm{c}$ leads to win against any type $\mathrm{x}_{1} \leq \mathrm{c}-\mathrm{K}$, regardless of the small perturbations introduced. If $\mathrm{x}_{2}>\mathrm{d}$, winning leads to a positive payoff regardless of the small perturbations on player 1's strategy (because he gets something close to $x_{2}-d$ ). But, if $x_{2}=d$, player 2's payoff is ( $d+x_{1}$-player 1's bid). For this payoff to be positive or null, it is enough to introduce perturbations on player 1's bids, such that she bids a little less than $\mathrm{x}_{1}+\mathrm{d}$ when $\mathrm{x}_{1} \leq \mathrm{c}-\mathrm{K}$.

It follows that each equilibrium of the above family is perfect, hence it is robust to slight modifications in the opponent's strategy. In order to get perfection, it is enough to introduce small perturbations such that player 1 bids a little less than $\mathrm{x}_{1}+\mathrm{d}$ when $\mathrm{x}_{1} \leq \mathrm{c}-\mathrm{K}$, and small perturbations such that player 2 bids a little more than $\mathrm{x}_{2}+\mathrm{c}$ when $\mathrm{x}_{2} \geq \mathrm{d}$.

\subsection{Naïve bidding and level $-k$ reasoning}

The set of equilibria of Proposition 4 (and Proposition 1), at least if the private signals are uniformly distributed on [0,1], gives partial support to the naïve bidding behaviour which consists to bid the private signal plus the expected value of the opponent's signal ( $1 / 2)$. For $\mathrm{K} \neq 0$, two equilibria partially support naïve bidding. They are given below and displayed in Figure $4 \mathrm{a}$ and Figure $4 \mathrm{~b}$.

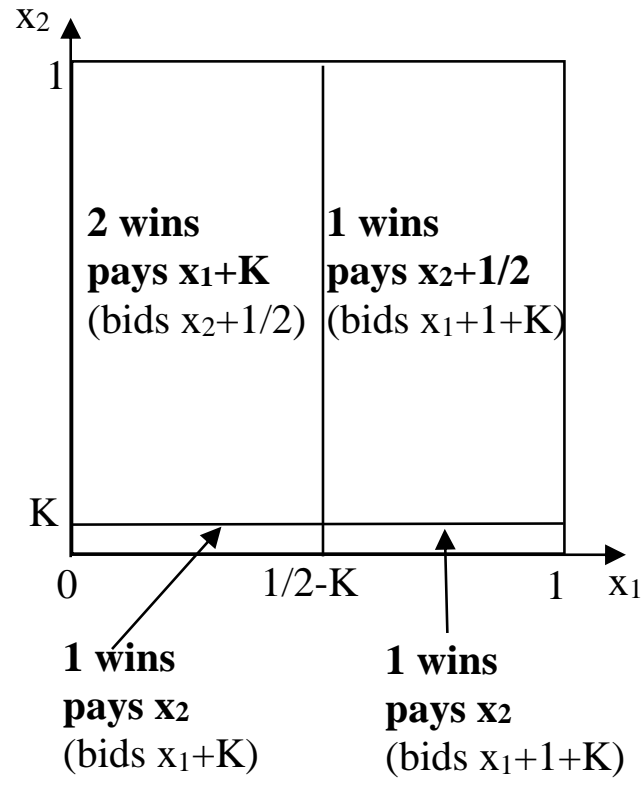

Figure $4 \mathrm{a}$

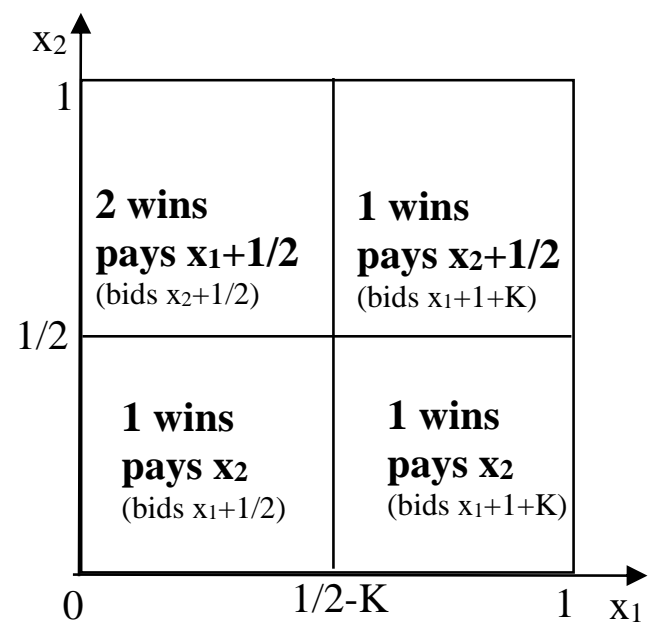

Figure $4 b$ 
First equilibrium, $\mathbf{E}_{\mathbf{N} 1}$ (Figure $4 \mathrm{a}$ )

Player 1 bids $\begin{aligned} \mathrm{b}_{1}\left(\mathrm{x}_{1}\right) & =\mathrm{x}_{1}+1+\mathrm{K} & & \text { if } \mathrm{x}_{1}>1 / 2-\mathrm{K} \\ & =\mathrm{x}_{1}+\mathrm{K} & & \text { if } \mathrm{x}_{1} \leq 1 / 2-\mathrm{K}\end{aligned}$

Player 2 bids $b_{2}\left(x_{2}\right)=x_{2}+1 / 2 \quad$ if $x_{2} \geq K$

$=\mathrm{x}_{2} \quad$ if $\mathrm{x}_{2}<\mathrm{K}$

Second equilibrium, EN2 (Figure $4 b$ )

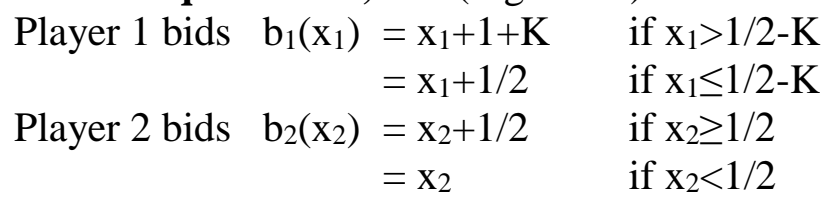

In both equilibria, a price $(x+1 / 2)$ is paid half of the time. In $E_{N 1}$, only player 2 bids naïvely (almost regardless of his private signal) whereas player 1 bids $\mathrm{x}_{1}+\mathrm{K}$ or $\mathrm{x}_{1}+1+\mathrm{K}$. In $\mathrm{E}_{\mathrm{N} 2}$, each player bids $\mathrm{x}+1 / 2$ at least part of the time. More precisely, player 1 bids $\mathrm{x}_{1}+1 / 2$ when her type is rather low, i.e. lower or equal to $1 / 2-\mathrm{K}$, whereas player 2 bids in this way when his type is rather high, i.e. higher or equal to $1 / 2$.

Note that for $\mathrm{K}=0$, Proposition 1 leads to three Nash equilibria with naïve behaviour, $\mathrm{E}_{\mathrm{N} 1}$ and $E_{N 2}$ with $K=0$, and $E_{N 3}$, symmetric to $E_{N 1}$, where player 1 bids $x_{1}+1 / 2$ regardless of the value of $\mathrm{x}_{1}$ and player 2 bids $\mathrm{x}_{2}$ if $\mathrm{x}_{2} \leq 1 / 2$ and $\mathrm{x}_{2}+1$ if $\mathrm{x}_{2}>1 / 2$.

Consider again $\mathrm{E}_{\mathrm{N} 1}$ when $\mathrm{K}$ goes to $0 . \mathrm{E}_{\mathrm{N} 1}$ then fits with level- $k$ reasoning (see Crawford and Iriberri 2007), where player 2 bids like an L1 player and player 1 bids like an L2 player. According to level- $k$ reasoning, players are rational - they best respond to their beliefs- but they base their beliefs on simplified models of behaviour of other players. Hence an L1 player best responds to an L0 player, an L2 player best responds to an L1 player, and so on. Of course the way one defines the L0 player is very important, because it determines the behaviour of all the higher level players.

So let us assume that an L0 player bids very naively, in that he bids the expected value of the wallet, i.e. $1 / 2+1 / 2=1$, regardless of his private signal. In that case an L1 player, whose private signal is $\mathrm{x}$, gets $\mathrm{x}+1 / 2-1$ if he bids more than 1 , and 0 if he bids less than 1 . It follows that one possible best response is: $b(x)=x+1 / 2$ (in order to bid more than 1 if $x>1 / 2$ and less than 1 if $\mathrm{x}<1 / 2$ ). Hence, in $\mathrm{E}_{\mathrm{N} 1}$, player 2 behaves like an L1 player. An L2 player best responds to an L1 player. Given that $\mathrm{E}_{\mathrm{N} 1}$ is a Nash equilibrium, player 1 best responds to player 2 and it immediately follows that player 1 behaves like an L2 player.

Hence $\mathrm{E}_{\mathrm{N} 1}$ can be viewed as a level-k profile of behaviours, where player 2 is an L1 player who best responds to an L0 player who just bids 1, regardless of his private signal, and player 1 is an L2 player who best responds to an L1 player. Yet, by contrast to Crawford and Iriberri's observation - "a level -k model's predictions ....in games as complex as auctions may deviate systematically from equilibrium" - these L1 and L2 behaviours constitute a Nash equilibrium because an L1 player not only best responds to the bid 1 but he also best responds to the L2 bidding strategy (in other words L1 players are also L3 players, which characterizes a Nash equilibrium). So we get here a special case where level-k reasoning fits with Nash equilibrium. 
Finally, we observe that a simple learning process with different speeds of learning can also lead to $\mathrm{E}_{\mathrm{N} 1}$.

Assume that both players, at the beginning, bid $x+1 / 2-$ which is often the case when a common value game is played for the first time - because each player takes into account the value of her/his private signal and simply adds the expected value of the signal of the other player.

Suppose also that one of the players (player 1) learns fast, whereas the other player (player 2) learns very slowly. In that case, player 1 promptly switches to her behaviour in $E_{N 1}$ so that player 2, when he learns (which only happens after player 1's change in behaviour), stays on $\mathrm{x}+1 / 2$, his behaviour in the $\mathrm{E}_{\mathrm{N} 1}$ equilibrium. Thus both players play the $\mathrm{E}_{\mathrm{N} 1}$ strategies and no player is no longer induced to change his/her behaviour: so a simple best response learning process with different speeds of learning can lead to $\mathrm{E}_{\mathrm{N} 1}$.

\section{Conclusion}

To summarize, in a second-price sealed-bid almost common value auction, Bikhchandani's explosive effect is not necessarily observed. To prove it, we introduce discontinuities in the bid functions. The presence of a slight advantage $(K>0)$ has an impact on the number of possible discontinuities: whereas one can introduce any number of discontinuities in the bid functions when $\mathrm{K}=0$ - so that the well-known continuous symmetric equilibrium appears in the limit -, one can only introduce one discontinuity when one player has a private advantage $(\mathrm{K}>0)$.

Nevertheless the new equilibria with one discontinuity obtained in Proposition 4 (for $K>0$ ) share interesting properties, which are far from those obtained by Bikhchandani (1988) and Klemperer(1998) : both players can win the auction; the price paid at equilibrium may be high, there is no ex-post regret, and the seller, at one of those equilibria, gets almost the same payoff as in the symmetric equilibrium $E_{S}$ of the common value auction game. As $\mathrm{K}$ (the slight advantage) grows, the minimal areas in which player 1 wins the auction (see Figure 2c) grow in size (because $d \geq K$, and $c-K \leq 1-K$ ), but in a proportional way instead of the announced explosive way. And we did not need to add additional regular bidders in order to get this result, as proposed in Levin and Kagel (2005), who managed to dampen the explosive effect but by adding more players.

Our family of equilibria is upper semi continuous at $\mathrm{K}=0$ and it even gives partial support to the naïve bidding strategy $\mathrm{x}+1 / 2$. One of the equilibria, $\mathrm{E}_{\mathrm{N} 1}$, supports level-k reasoning, with player 2 being an L1 player and player 1 an L2 player.

\section{Acknowledgements}

Paul Pezanis-Christou and two referees are gratefully acknowledged for their helpful comments. 


\section{Bibliography}

Avery, C., Kagel, J.H. (1997) Second price auctions with asymmetric payoffs: an experimental investigation, Journal of Economics and Management Strategy, 6 (3), 573-603. Bikhchandani, S. (1988) Reputation in repeated second-price auctions, Journal of Economic Theory, 46, 97-119.

Crawford, V.P., Iriberri, N. (2007) Level-k auctions: can a non-equilibrium model of strategic thinking explain the winner's curse and overbidding in private-value auctions? Econometrica, 75 (6,) 1721-1770.

Klemperer, P. (1998) Auctions with almost common values: the wallet game and its applications, European Economic Review, 42, 757-769

Levin, D., Kagel, J.H. (2005) Almost common values auctions revisited, European Economic Review, 49, 1125-1136.

Rose, S.L., Kagel, J.H. (2008) Almost common value auctions: an experiment, Journal of Economics and Management Strategy, 17 (4), 1041-1058.

Rose S.L., Levin D. (2008) An experimental investigation of the explosive effect in almost common value auctions, Journal of Economic Behavior and Organization, 67, 927-946.

Selten, R. (1975) Re-examination of the perfectness concept for equilibrium points in extensive games, International Journal of Game Theory, 4, 25-55.

\section{Appendix A}

\section{Proof of Proposition 2}

Let us fix, w.1.o.g. $i=1$ and $j=2$.

We first establish that $\mathrm{b}_{1}\left(\mathrm{x}_{1}\right)$ a best response:

- If $\mathrm{x}_{1}>\mathrm{c}_{\mathrm{N}}$, player 1 wins the auction because she bids more than any type of player 2 , given that player 2 's highest bid is $1+\mathrm{c}_{\mathrm{N}}$; and she is best off winning the auction because she gets at least $\mathrm{x}_{1}-\mathrm{c}_{\mathrm{N}}>0$.

- If $\mathrm{c}_{\mathrm{N}-\mathrm{k}-1}<\mathrm{x}_{1} \leq \mathrm{c}_{\mathrm{N}-\mathrm{k}}$ with $\mathrm{k}$ from 0 to $\mathrm{N}-2$, she wins against any type of player 2 with $\mathrm{x}_{2}<\mathrm{d}_{\mathrm{N}-\mathrm{k}}$ because she bids more than $\mathrm{c}_{\mathrm{N}-\mathrm{k}+1}+\mathrm{d}_{\mathrm{N}-\mathrm{k}}$ whereas player 2 bids less, and winning is her best strategy because she gets at least $\mathrm{x}_{1}-\mathrm{c}_{\mathrm{N}-\mathrm{k}-1}>0$.

But she loses the auction if $\mathrm{x}_{2} \geq \mathrm{d}_{\mathrm{N}-\mathrm{k}}$ and $\mathrm{x}_{1}<\mathrm{c}_{\mathrm{N}-\mathrm{k}}$ because she bids less than $\mathrm{c}_{\mathrm{N}-\mathrm{k}}+\mathrm{d}_{\mathrm{N}-\mathrm{k}}$, whereas player 2 bids at least this amount, and she is best off losing the auction because winning would at best lead to the payoff $\mathrm{x}_{1}-\mathrm{c}_{\mathrm{N}-\mathrm{k}}<0$. If $\mathrm{x}_{1}=\mathrm{c}_{\mathrm{N}-\mathrm{k}}$ and $\mathrm{x}_{2}>\mathrm{d}_{\mathrm{N}-\mathrm{k}}$, she loses the auction because player 2's bid is higher than her bid $\mathrm{c}_{\mathrm{N}-\mathrm{k}}+\mathrm{d}_{\mathrm{N}-\mathrm{k}}$ and she is best off losing because winning would at best lead to a null payoff. If $\mathrm{x}_{1}=\mathrm{c}_{\mathrm{N}-\mathrm{k}}$ and $\mathrm{x}_{2}$ $=\mathrm{d}_{\mathrm{N}-\mathrm{k}}$, then she makes the same bid as player 2. Proposition 2 does not specify how the wallet is shared in case of a tie. But this is of no importance because player 1 gets 0 , whether getting or not getting the wallet.

- If $\mathrm{x}_{1} \leq \mathrm{c}_{1}$, she wins against any type of player 2 such that $\mathrm{x}_{2}<\mathrm{d}_{1}$ (because she bids at least $d_{1}$ and player 2 bids less) and winning is the best strategy because she gets $\mathrm{x}_{1} \geq 0$. She loses against any type of player 2 such that $\mathrm{x}_{2}>\mathrm{d}_{1}$ because player 2 bids more than $\mathrm{c}_{1}+\mathrm{d}_{1}$, and losing is the best strategy because winning leads to the payoff $\mathrm{x}_{1}-\mathrm{c}_{1} \leq 0$. For similar reasons, if $\mathrm{x}_{2}=\mathrm{d}_{1}$ and $\mathrm{x}_{1}<\mathrm{c}_{1}$, she loses the auction and is happy to lose (she bids less than player 2 's bid $\mathrm{c}_{1}+\mathrm{d}_{1}$ and would get $\mathrm{x}_{1}-\mathrm{c}_{1}<0$ upon winning). And if $\mathrm{x}_{1}=\mathrm{c}_{1}$ and $\mathrm{x}_{2}=\mathrm{d}_{1}$, both players bid $\mathrm{c}_{1}+\mathrm{d}_{1}$, and player 1 gets 0 , whether she gets or not the wallet (Proposition 2 does not specify how to share the wallet in case of a tie). 
We now establish that $\mathrm{b}_{2}\left(\mathrm{x}_{2}\right)$ is a best response:

- If $\mathrm{x}_{2} \geq \mathrm{d}_{\mathrm{N}}$, player 2 bids less than any type of player 1 such that $\mathrm{x}_{1}>\mathrm{c}_{\mathrm{N}}$, because he bids at most $1+\mathrm{c}_{\mathrm{N}}$, and player 1 bids more. Losing the auction is his best strategy because winning would lead to the payoff $\mathrm{x}_{2}-1 \leq 0$. And player 2 bids more than any type of player 1 such that $\mathrm{x}_{1}<\mathrm{c}_{\mathrm{N}}$ because he bids at least $\mathrm{c}_{\mathrm{N}}+\mathrm{d}_{\mathrm{N}}$ and player 1 bids less. And winning is the best strategy because he gets at least $x_{2}-d_{N} \geq 0$. If $x_{1}=c_{N}$, and $x_{2}>d_{N}$, he wins the auction because he bids more than player 1 and winning is the best strategy because he gets $\mathrm{x}_{2}-\mathrm{d}_{\mathrm{N}}>0$. If $\mathrm{x}_{1}=\mathrm{c}_{\mathrm{N}}$ and $\mathrm{x}_{2}=\mathrm{d}_{\mathrm{N}}$, both players make the same bid and player 2 gets 0 , whether getting or not getting the wallet (given that Proposition 2 does not specify how to share the wallet in case of a tie).

- If $\mathrm{d}_{\mathrm{N}-\mathrm{k}-1} \leq \mathrm{x}_{2}<\mathrm{d}_{\mathrm{N}-\mathrm{k}}$ with $\mathrm{k}$ from 0 to $\mathrm{N}-2$, player 2 bids less that any type of player 1 such as $\mathrm{c}_{\mathrm{N}-\mathrm{k}-1}<\mathrm{x}_{1}$, because he bids less than $\mathrm{d}_{\mathrm{N}-\mathrm{k}}+\mathrm{c}_{\mathrm{N}-\mathrm{k}-1}$ whereas player 1 bids more. And losing the auction is the best strategy because winning would at best lead to the payoff $\mathrm{x}_{2}-\mathrm{d}_{\mathrm{N}-\mathrm{k}}<0$.

And player 2 bids more than any type of player 1 such as $\mathrm{x}_{1}<\mathrm{c}_{\mathrm{N}-\mathrm{k}-1}$, because he bids at least $\mathrm{d}_{\mathrm{N}-\mathrm{k}-1}+\mathrm{c}_{\mathrm{N}-\mathrm{k}-1}$ (and player 1 bids less) and winning is his best strategy because he gets at least $\mathrm{x}_{2}-\mathrm{d}_{\mathrm{N}-\mathrm{k}-1} \geq 0$.

If $\mathrm{x}_{1}=\mathrm{c}_{\mathrm{N}-\mathrm{k}-1}$ and $\mathrm{x}_{2}>\mathrm{d}_{\mathrm{N}-\mathrm{k}-1}$, player 2 wins the auction because his bid is higher than player 1 's, $\mathrm{d}_{\mathrm{N}-\mathrm{k}-1}+\mathrm{c}_{\mathrm{N}-\mathrm{k}-1}$, and winning is the best strategy because he gets $\mathrm{x}_{2}-\mathrm{d}_{\mathrm{N}-\mathrm{k}-1}>0$. And if $\mathrm{x}_{1}=\mathrm{c}_{\mathrm{N}-\mathrm{k}-1}$ and $\mathrm{x}_{2}=\mathrm{d}_{\mathrm{N}-\mathrm{k}-1}$, then both players bid $\mathrm{d}_{\mathrm{N}-\mathrm{k}-1}+\mathrm{c}_{\mathrm{N}-\mathrm{k}-1}$ and player 2 gets 0 , whether he gets or not the wallet (given that Proposition 2 does not specify how to share the wallet in case of a tie).

- If $\mathrm{x}_{2}<\mathrm{d}_{1}$, player 2 bids less than any type of player 1 and losing the auction is his best strategy because winning would at best lead to the payoff $\mathrm{x}_{2}-\mathrm{d}_{1}<0$.

And no strategy is dominated, given that each player of type $\mathrm{x}$ bids an amount between $\mathrm{x}$ and $\mathrm{x}+1$.

\section{Appendix B}

\section{Proof of Proposition 4}

We first establish that $\mathrm{b}_{1}\left(\mathrm{x}_{1}\right)$ is a best response:

If $\mathrm{x}_{1}>\mathrm{c}-\mathrm{K}$ player 1 best replies against any type of player 2 because:

- First she wins against any type of player 2, because $x_{1}+1+K>c+1$ and player 2 never bids more than $\mathrm{c}+1$.

- Second, she earns a positive payoff by winning, because she gets either $\mathrm{x}_{1}+\mathrm{x}_{2}+\mathrm{K}-\mathrm{x}_{2}-$ $\mathrm{c}$ or $\mathrm{x}_{1}+\mathrm{x}_{2}+\mathrm{K}-\mathrm{x}_{2}$ depending on player 2's type, which are both positive.

If $\mathrm{x}_{1} \leq \mathrm{c}-\mathrm{K}$ :

- She loses against any type of player 2 such that $\mathrm{x}_{2} \geq \mathrm{d}$, because $\mathrm{x}_{1}+\mathrm{d} \leq \mathrm{c}-\mathrm{K}+\mathrm{d}$ and $\mathrm{x}_{2}+\mathrm{c}$ $\geq \mathrm{d}+\mathrm{c}$. And losing gives her the best payoff, 0 , because winning would lead to the payoff $\mathrm{x}_{1}+\mathrm{x}_{2}+\mathrm{K}-\mathrm{x}_{2}-\mathrm{c} \leq 0$.

- She wins against any type of player 2 such that $\mathrm{x}_{2}<\mathrm{d}$, because $\mathrm{x}_{2}<\mathrm{d} \leq \mathrm{x}_{1}+\mathrm{d}$, and she gets a positive payoff by winning, given that $\mathrm{x}_{1}+\mathrm{x}_{2}+\mathrm{K}-\mathrm{x}_{2}>0$.

We now establish that $\mathrm{b}_{2}\left(\mathrm{x}_{2}\right)$ is a best response:

If $\mathrm{x}_{2} \geq \mathrm{d}$ :

- Player 2 loses against any type of player 1 such that $\mathrm{x}_{1}>\mathrm{c}-\mathrm{K}$ (see above). And he is best off losing, because winning would lead to the payoff $\mathrm{x}_{2}+\mathrm{x}_{1}-\mathrm{x}_{1}-1-\mathrm{K}<0$. 
- He wins against player 1 if $\mathrm{x}_{1} \leq \mathrm{c}-\mathrm{K}$ (see above); and he is best off winning because he gets $\mathrm{x}_{2}+\mathrm{x}_{1}-\mathrm{x}_{1}-\mathrm{d} \geq 0$.

If $\mathrm{x}_{2}<\mathrm{d}$, he loses against any type of player 1 (see above), and he is best off losing because, by winning, he would get $\mathrm{x}_{2}+\mathrm{x}_{1}-\mathrm{x}_{1}-\mathrm{d}<0$, if facing a player 1 type $\mathrm{x}_{1} \leq \mathrm{c}-\mathrm{K}$, and he would get $\mathrm{x}_{2}+\mathrm{x}_{1}-\mathrm{x}_{1}-1-\mathrm{K}<0$ if facing a player 1 type $\mathrm{x}_{1}>\mathrm{c}-\mathrm{K}$.

The equilibrium contains no weakly dominated strategy given that player 1's bid is between $\mathrm{x}_{1}+\mathrm{K}$ and $\mathrm{x}_{1}+1+\mathrm{K}$, and player 2 's bid is between $\mathrm{x}_{2}$ and $\mathrm{x}_{2}+1$.

\section{Appendix C}

\section{Proof of Proposition 5}

Let us generalise the bidding strategies of Figure 1 to bidding strategies with any number of discontinuities. The case with two discontinuities is illustrated in Figure 5.

The key feature of Figure 5 is the shaded area, which includes the segments [FG] and [HI] and the points $\mathrm{E}$ and $\mathrm{J}$, and which doesn't exist in figure 1. It is immediate that similar shaded areas exist for any number of discontinuities higher than one ( $n-1$ shaded areas for $n$ discontinuities).

In what follows, attention will be focused on Figure 5's shaded area to show that the bidding strategies in this area are incompatible with no ex-post regret Nash equilibrium. So, given that $\mathrm{n}$ discontinuities lead to $\mathrm{n}-1$ similar areas, we prove the nonexistence of equilibria with $\mathrm{n}$ discontinuities simply by focusing on the case with 2 discontinuities.

It actually comes out that we only need to prove that the bidding strategies associated with player 1's type $\mathrm{C}_{1}$ and player 2's type $\mathrm{D}_{2}$ are not compatible with a Nash equilibrium with no ex-post regret.

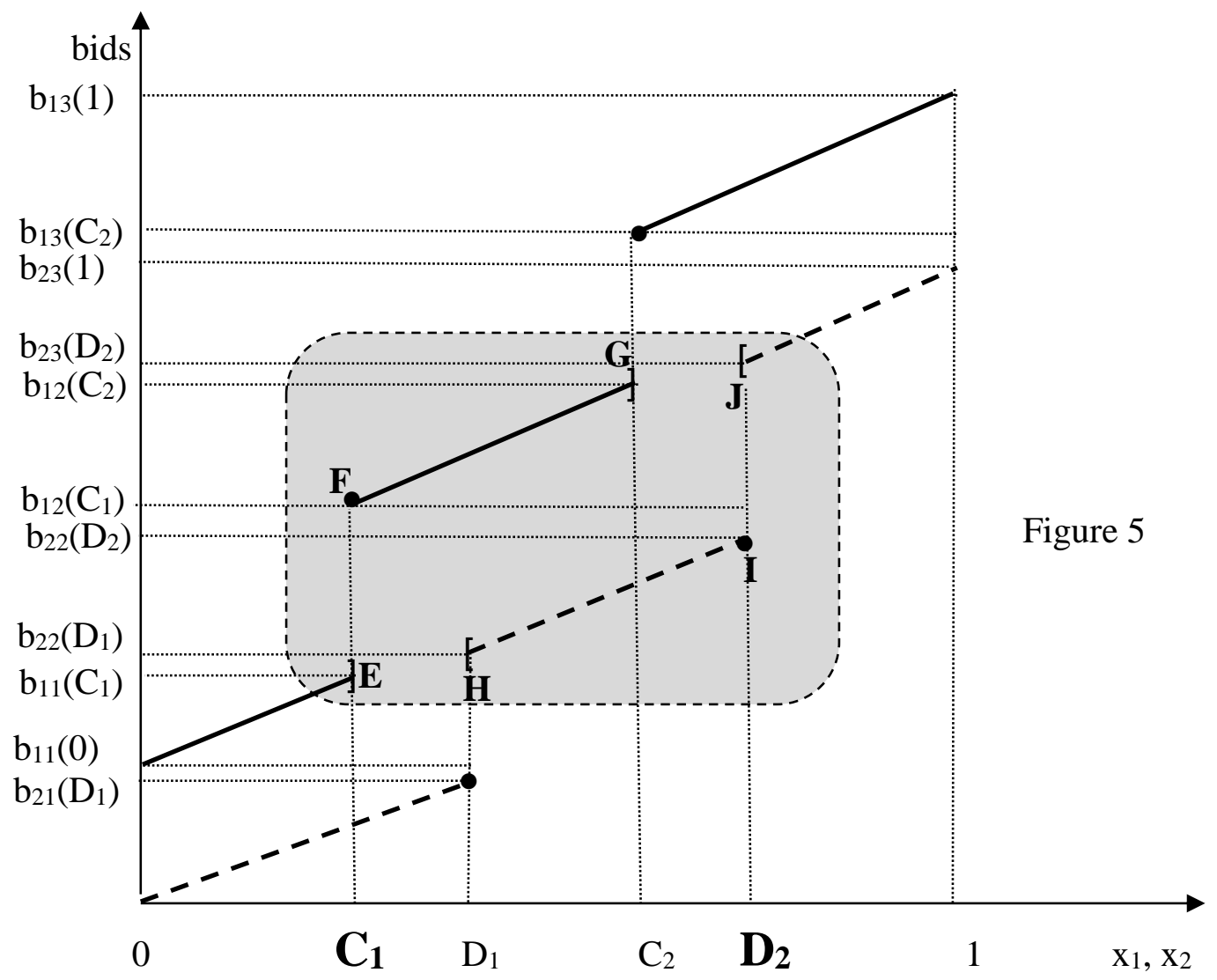


Legend of Figure 5: • means that the point is excluded, a bracket means that it is included. The full lines are player 1 's bids, the dashed lines are player 2 's bids.

Let us precise the bidding behaviour:

Player 1 bids:

$\mathrm{b}_{13}\left(\mathrm{x}_{1}\right)$ if $\mathrm{x}_{1}>\mathrm{C}_{2}$

$\mathrm{b}_{12}\left(\mathrm{x}_{1}\right)$ if $\mathrm{C}_{1}<\mathrm{x}_{1} \leq \mathrm{C}_{2} \quad$ with $\mathrm{b}_{13}\left(\mathrm{C}_{2}\right)>\mathrm{b}_{12}\left(\mathrm{C}_{2}\right)$

$\mathrm{b}_{11}\left(\mathrm{x}_{1}\right)$ if $\mathrm{x}_{1} \leq \mathrm{C}_{1} \quad$ with $\mathrm{b}_{12}\left(\mathrm{C}_{1}\right)>\mathrm{b}_{11}\left(\mathrm{C}_{1}\right)$

Player 2 bids:

$\mathrm{b}_{23}\left(\mathrm{x}_{2}\right)$ if $\mathrm{x}_{2} \geq \mathrm{D}_{2}$

$\mathrm{b}_{22}\left(\mathrm{x}_{2}\right)$ if $\mathrm{D}_{1} \leq \mathrm{x}_{2}<\mathrm{D}_{2} \quad$ with $\mathrm{b}_{23}\left(\mathrm{D}_{2}\right)>\mathrm{b}_{22}\left(\mathrm{D}_{2}\right)$

$\mathrm{b}_{21}\left(\mathrm{x}_{2}\right)$ if $\mathrm{x}_{2}<\mathrm{D}_{1} \quad$ with $\mathrm{b}_{22}\left(\mathrm{D}_{1}\right)>\mathrm{b}_{21}\left(\mathrm{D}_{1}\right)$

with $b_{i j}\left(x_{i}\right), i=1,2, j=1,2,3$ increasing continuous functions in $x_{i}$.

Given that we try to generalize the equilibria of Proposition 4 in order to come close to equilibria of Proposition 2, we have $b_{12}\left(C_{1}+\right) \geq b_{22}\left(D_{2}-\right)$, with $C_{1}+$ close to $C_{1}$ (and $C_{1}+>C_{1}$ ) and $D_{2}$ - close to $D_{2}$ (and $D_{2}-\left\langle D_{2}\right.$ ). By continuity of the functions $b_{i j}\left(x_{j}\right), i=1,2, j=1,2,3$, it follows that $b_{12}\left(C_{1}\right) \geq b_{22}\left(D_{2}\right)$.

Now let us focus on player 1 of type $C_{1}$ and player 2 of type $D_{2}$ (the types associated to the points $\mathrm{E}$ and $\mathrm{J}$ ).

Player 1 of type $\mathrm{C}_{1}+$ bids more than any type of player 2 in $\left[\mathrm{D}_{1} \mathrm{D}_{2}\right)$; so, given the no ex-post regret property, $C_{1}+$ has to get a positive or null payoff when she faces $D_{2-}$, i.e. $C_{1}+K+D_{2}$ $b_{22}\left(D_{2}\right) \geq 0$ given the continuity of the bid functions. And player 1 of type $C_{1}$ has to get a negative or null payoff when she faces any type of player 2 in $\left[D_{1} D_{2}\right.$ ) (because she bids less and loses the auction). So she has to get a negative or null payoff when she faces $\mathrm{D}_{2^{-}}$, hence $\mathrm{C}_{1}+\mathrm{K}+\mathrm{D}_{2}-\mathrm{b}_{22}\left(\mathrm{D}_{2}\right) \leq 0$ given the continuity of the bid functions.

It thus follows that $\mathrm{C}_{1}+\mathrm{K}+\mathrm{D}_{2}-\mathrm{b}_{22}\left(\mathrm{D}_{2}\right)=0$.

Player 2 of type $\mathrm{D}_{2}$ bids more than any type of player 1 in $\left(\mathrm{C}_{1}, \mathrm{C}_{2}\right]$, so, given the no ex-post regret property, $D_{2}$ has to get a positive or null payoff when he faces $C_{1}+$, i.e. $C_{1}+D_{2}-b_{12}\left(C_{1}\right) \geq$ 0 given the continuity of the bid functions. And player 2 of type $\mathrm{D}_{2-}$ has to get a negative or null payoff when he faces any type of player 1 in $\left(\mathrm{C}_{1}, \mathrm{C}_{2}\right]$. So he has to get a negative or null payoff when he faces $C_{1}+$; hence $C_{1}+D_{2}-b_{12}\left(C_{1}\right) \leq 0$ given the continuity of the bid functions. It thus follows that $\mathrm{C}_{1}+\mathrm{D}_{2}-\mathrm{b}_{12}\left(\mathrm{C}_{1}\right)=0$.

Given that $b_{12}\left(C_{1}\right) \geq b_{22}\left(D_{2}\right)$, from (1) and (2) we get:

$\mathrm{b}_{12}\left(\mathrm{C}_{1}\right)=\mathrm{C}_{1}+\mathrm{D}_{2} \geq \mathrm{b}_{22}\left(\mathrm{D}_{2}\right)=\mathrm{C}_{1}+\mathrm{K}+\mathrm{D}_{2}$ which is clearly impossible, given $\mathrm{K}>0$.

Let us add that, to get this result, we do not need the linear bid functions illustrated in Figure 5: the proof works with any increasing continuous bid functions $b(x)$. 